\title{
TRANSFORMATION OF SYSTEMS OF INTERACTIVE SIMULATION OF CONFLICT SITUATIONS INTO SYSTEMS BASED ON DECISION PATTERNS
}

\author{
Andrzej Najgebauer \\ Military University of Technology, Faculty of Cybernetics, Institute of Computer and Information Systems \\ 00-908 Warsaw, Kaliskiego 2 Street, Poland
}

\begin{abstract}
The simulation can be observed as a type of intelligence, where software there is a mind and hardware there is a body. The limitations of such intelligence are concerned. The researches cover the process of construction, testing and experimentation with the simulation system, towards knowledge extraction. The technological line of conflict analysis with different computer tools utilization is presented. The central part of the line there is an interactive simulation environment for the analysis (and/or training) of military operations. The idea of interactive simulation for land operations and its exemplification there is presented. The necessity and requirements for computer environment were described. Possible directions and solutions of these environments are presented. On the basis of own methodology for simulation system designing and development, simulation systems MSCombat (as prototype) and Złocień, SWDT as professional systems were built and tested. The methodology consists of eight phases - the general description of a conflict, the conflict model as non-coalition 3-person game, the model of battle process - the multidimensional stochastic process, the decision model - the multiple stage stochastic optimization problem, the computer environment for simulation of combat process, the experiments, monitoring and visualization phase, the post-simulation analysis.. In the environment it is possible to examine different approaches and models because the construction is modular and object-oriented. The chosen phases of analysis, definition, modelling and implementation of professional system are presented in the paper. The directions of transformation of the simulation environment into the artificial intelligence are proposed.
\end{abstract}

\section{KEYWORDS}

Interactive Simulation, Decision Support, Decision Patterns, Systems Analysis and Modelling

\section{INTRODUCTION}

The simulation as mentioned, can be observed as a type of intelligence, where software there is a mind and hardware there is a body (Penrose R., 1989). The limitations of such intelligence should be concerned. A military conflict can be concerned as a complex adaptive system (Ilachinski J, 1996). The author formulated some hypotheses, that military conflict can be characterized by:

- non-linear interaction of combat components (measure --> counter-measure --> counter-countermeasure--> ...)

- $\quad$ hierarchical structure of command and control

- decentralized control

- $\quad$ self-organization (long range order)

- $\quad$ non-equilibrium order

- $\quad$ adaptation

- $\quad$ collectivism

The main conclusion of these consideration is:

there exists commander's battlefield intuition as ability to perceive some patterns - that is the basis of thinking about an extraction of decision rules in military conflicts. Some very important concepts of combat modelling are presented in (Dockery at al, 1993).

We would like to test the hypotheses, so it is required to conduct very sophisticated researches. The researches cover the process of construction, testing and experimentation with the simulation system, towards knowledge extraction. The technological line of conflict analysis with different computer tools utilization is 
presented. The central part of the line there is an interactive simulation environment for the analysis (and/or training) of military operations. The fundamental questions of the analysis and computer support of the conflict analysis were put:

- How to identify the real conflict situation?

- How to reflect the situation?

- How to determine the best decisions?

- What type of criteria should we take into account?

- What a sense do the decisions have under uncertainty conditions?

- $\quad$ How to decompose the complex situations into local type situations?

- What type of local conflict models should we use in the situation?

- Do any patterns of behavior exist in a decision situation?

- How to reflect uncertainty and surprise in a conflict situation?

- How to show the dynamics and changes in a situation?

- Where are the limits of the computer simulation and our belief in efficacy of that type of conflict analysis?

The answers for the questions consist in the specific methodology of the analysis and computer support proposed.

The phases of the methodology are as follows:

- the general description and identification of a conflict

- $\quad$ the conflict model as non-coalition n-person game (as the start point)

- $\quad$ the model of battle process - the multidimensional stochastic process

- $\quad$ the decision model - the multiple stage stochastic optimisation problem with risk criteria

- the computer environment for simulation of combat process

- $\quad$ the experiments, monitoring and visualization phase

- the post-simulation analysis

The transition between the stochastic model and simulation model is realized during the implementation phase. Many characteristics of the military conflict modelled are random variables or stochastic processes. So it is necessary to use random generators with different distributions. The direction of transformation of the simulation environment into the artificial intelligence is proposed. The simulation system can be defined as a formal system and it undergoes the same limits like another formal system. The famous German mathematician - Hilbert formulated e.g. Entscheidungsproblem, which consists in the question:

Does exist the automatic procedure, which allows to resolve all the mathematical problems, belonging into the wide, well defined class? (Hilbert, 1900, 1928).

The thesis of Church and Turing and also the Gödel's theorem, that everyone formal system, consisting of natural number arithmetic isn't complete, so contains indeterminate formulas (1931) show us the limits of computer simulation as formal system.

The modern battle-winning forces must be adequately trained and equipped. The changes in defense climate in recent years have placed greater emphasis on the use of modelling and simulation to explore training and justify chosen solutions. In fact, since reality is infinitely complex, especially a conflict situation, all human decision-making is based on models. In most cases these are mental models that we construct but they are rarely fully defined and usually qualitative in nature. The analytical model, in contrast, is fully defined, open to examination and challenge, and to maximum extent possible, quantitative (G.P. Hawkins, 2000). The essence of the analytical process is to bring together in a systematic and auditable way a range of data, assumptions and judgements relevant to the problem and to demonstrate their implications and interrelationships. Analytical models and closed constructive models offer speed, controllability, repeatability, flexibility and relatively low cost, and are usually the preferred option. Unfortunately the real situations are very complicated and it is necessary to use simulation models, which are more flexible in examining procurement options or different concept of operations. This type of analysis is repeatable.

Simulations in military domain can be divided into three types:

- $\quad$ Live - real people operating real equipment, platforms or systems, usually on tactical or weapons ranges.

- Virtual - real people operating simulated systems. The latter may include any mix of equipment, system or platform simulators, rigs or testbeds, computer presentations/visualizations or prototypes of the same, factories and production lines, and/or constructive models of forces or force elements. 
- $\quad$ Constructive - simulated people operating simulated equipment, or systems. Computer models represent the actions of people and/or equipment using mathematical equations and/or logical algorithms.

Distributed interactive simulation is a technology develop by military experts to facilitate the integration and use of multiple simulations and simulators in a distributed collaborative computing environment. Synthetic environments extend the modelling and simulation concept by integrating consistent sets of models, simulations, people and real equipment within a common representation of the world. The consistent set is assembled from three types of components:

- a framework (architecture, standards, communications) with which all components must comply, so that they can interoperate.

- a world, reflecting the properties of the real environment, usually a "battlespace", including physical feature (such as terrain), phenomena (such as weather and smoke) and an operational context/scenario.

- participants i.e. equipment/systems (and/or their components), individuals, force elements and/or whole forces.

Synthetic environments can be constructed and operated at many levels of representation, aggregation and fidelity ranging from geopolitical analysis down to component-level action support and cost modelling.

In the paper I am focused on land operations (division and brigade). The commanders and their staffs should be trained, so it is proposed the construction specific computer environment on the basis of operational game model:

$$
\Gamma_{\mathrm{S}}=<N, M_{S W} S C_{W}>
$$

where: $N$ - a set of participants, the component of the set is determined by their role (head, trainee, observer, analyst, expert, opposing forces commander), personal data, team structure, if group participant;

$M_{S W}$ - campaign process model, which can be described by $S(t)$ (Najgebauer, 1999a) and set of complementary parameters

$S C_{W}$ - scenario of combat, which is defined as initial state of campaign process $S\left(t_{0}\right)$, termination time $T^{Y}$ ( $Y=A, B, C, \ldots$-participant of game notation) and mission from higher level $T^{Y}, \boldsymbol{S}_{\text {Sat }}\left(T^{Y}\right),(Y=A, B, C, \ldots)$

The phases of game construction ( Najgebauer, 1999a):

- Conceptual phase - the aim of game is determined.

- Data gathering - collecting of the conflict situation data, possible actions or counteractions, probable events on the battlefield..

- The situation model - verbal or mathematical model of the situation, possible relations, manoeuvre models, combat and logistics models, criteria of decision estimation

- The transformation of the situation model into operational game - the simplification, type of simulation, time procedures, methods of state update:

- guidelines, exercise team and service team determination, initial conditions, evaluation method determination, the method of combat success justification, the method of activity trace, the method of documentation, mission ordering, publication of guidelines.

- Game testing - the game designer examines the procedures and results of the game.

- Operational phase - scenario preparation and the experiment realisation.

\section{THE ANALYSIS AND PROBLEM DEFINITION}

The main subject of interests there are decision-making processes in armed conflict situations and the subject of evaluation there is decision-maker, who makes the decisions. The decision-making process in armed conflict is very complex, because of uncertainty, incomplete information and rate of combat.

The conflict situations cause many decisions problems. It is possible to support a commander in the process realising the analysis of probable moves and expected results of these moves. The attention is focused on valid reflection of decisions, made by commanders, who take part in the exercises. Computer simulations of the 
situation can support the commander in the complex process. The computer environment should be carefully designed to flexible and precise reflection of conflict situation and decision-makers interaction.

The interaction process in computer environment is one of decision updating method, when the decision-maker tries to react on changeable conditions of combat. In (Najgebauer, 1999a) the general decision procedure was proposed as a multistage decision problem. The results of decisions can be observed. The strategies of decision-makers (players) are formulated on the basis of a combat process model that is defined as a multivariate stochastic process. The stochastic model expresses the uncertainty in a conflict situation. There exists the possibility of observation of the battlefield and making decisions on the basis of these measurements. The general combat process presented below is a simplification of much more widely described process for the professional system Złocień. However there are much more sophisticated models are described and applied in the computer environments, which were built by my team. The simplification is used for the purpose of synthetic presentation of transformation problem and the way of modelling in the paper.

\subsection{General Combat Process}

Let $\{\boldsymbol{S}(\boldsymbol{t}), \boldsymbol{t} \in[\mathbf{0}, \boldsymbol{T}]\}$ be the multidimensional stochastic process (Najgebauer, 1999a,), where:

$$
\left\{S(t)=\left(S_{I Y}(t), S_{2 Y}(t), S_{3 Y}(t), S_{4 Y}(t), S_{S Y}(t), S_{6 Y}(t), S_{I P W}(t), S_{2 P W}(t)\right), t \in[0, T], Y=A, B\right\}
$$

$S_{I Y}(t)$ - number of combat units of side $Y(A, B)$ (they are ready to fight), $S_{I Y}(t) \in\left\{0,1,2, \ldots, M^{Y}\right\}, S_{2 Y}(t)$ - combat potential of side $Y, S_{2 Y}(t)=\left(S_{2 Y}^{1}(t), S_{2 Y}^{2}(t)\right) \quad S_{2 Y}(t) \in\left\{\left\{0, \bar{S}_{2 Y}^{1}\right\} \times\left\{0, \bar{S}_{2 Y}^{2}\right\}\right\}, S_{2 Y}^{1}(t)$ - combat potential of side $Y$ in an attack, $S_{2 Y}^{2}(t)$ - combat potential of side $Y$ in a defence, $S_{3 Y}(t)$ - state of readiness, $S_{3 Y}(t) \in\{0,1\}, S_{4 Y}(t)$ - efficacy degree of logistics system, $S_{4 Y}(t) \in\{1,2,3,4\}$, the levels of combat potential renewal in a period of time, $S_{5 Y}(t)$ - surveillance level, $S_{5 Y}(t) \in\{1,2, \ldots, 7\}$, the levels of enemy recognition, $S_{6 Y}(t)$ - combat units placement, $\quad S_{6 Y}(t)=\left(S_{6 Y}^{1}(t), S_{6 Y}^{2}(t), \cdots, S_{6 Y}^{i}(t), \cdots, S_{6 Y}^{H^{Y}}(t)\right), S_{6 Y}^{i}(t) \in H^{Y}=\{1,2,3,4,5,6\}, S_{I P W}(t)$ - the set of battlefield routes, $S_{1 P W}(t) \subset L=\left\{l_{1}, l_{2}, \cdots, l_{k}, \cdots, l_{K}\right\}, S_{2 P W}(t)$ - weather at the time $t, S_{2 P W}(t) \in\{1,2,3,4,5,6,7\}$ set of numbers of different types of weather.

\subsection{Terrain Model}

The terrain model is discrete and can be expressed as follows:

$$
Z=\left\langle G,\{\varphi\}_{l=1,2,3,}\{\varnothing\}\right\rangle
$$

where $\mathbf{G}=\langle W, U\rangle$ - Berge graph, $W$ - set of vertices , $U$ - set of arcs, $U \subset W \times W$

$\varphi_{1}: W \rightarrow \boldsymbol{C}$ - function, which describes a location of the zone, represented by vertex $w \in W, \boldsymbol{C} \subset R^{3}, \boldsymbol{C}$ describes the whole battlefield area of the conflict, $\varphi_{2}: W \rightarrow 2^{L}$ function, which describes an assignment of roads to node $w$ (these roads are accessible for mobility in a zone $w$ ), $\boldsymbol{L}$ - set of all road numbers in a battlefield, $\varphi_{3}: W \times$ $J^{A(B)} \rightarrow 2^{T U}$ - assignment function of formation type subset to node $w, \boldsymbol{T U}$ - set of all possible types of combat units formation, $\varphi_{4}: W \times J^{A(B)} \rightarrow R^{n}$ - the determination of maximal velocities of combat units on roads of battlefield, $\quad n=|\boldsymbol{L}|$. Arcs of the graph represent possibility of close transition between zones. The process is discrete in states and continuous in time (DC). Combat actions, decisions and their realizations, natural phenomena and so on causes the transitions between states. The phase space $\boldsymbol{X}$ of the process $S(t)$ can be represented as follows:

$$
\begin{aligned}
& \mathbf{X}=\left[\{0,1, \ldots, M\} \times\left\{0,1, \ldots, \overline{S_{2 Y}^{1}}\right\} \times\left\{0,1, \ldots . \overline{S_{2 Y}^{2}}\right\} \times\{0,1\} \times\{1,2,3,4\} \times\right. \\
& \left.\times\{1,2,3,4,5,6,7\} \times\{0,1\} \times \times\left(\mathbf{H}^{M}\right)^{Y}\right]^{2} \times 2^{\mathbf{L}} \times\{1,2,3,4,5,6,7\}
\end{aligned}
$$

Each element of the battle system, which represents one of the sides or the battlefield, can be represented as an object. The transitions of the combat process are connected with events on the battlefield and their time is random variable. One of the important sources of randomness on the battlefield there is random result of the local clash. We have proposed many stochastic models of the local conflict in a sense of locality as a closed combat process between two elementary combat units (process of combat units resource destroying). There are 
applied three models of local combat in the environment built for initial analysis. Now is built and developed new model of distributed interactive simulation system for CAX. So I propose the set of requirements, which should be realised to better (more adequate) reflection of conflict situation.

\subsection{Computer Assisted Exercises - Design of the Experimental Environment}

The process of designing environments for interactive distributed simulation can be presented in the form of diagrams (Figure 1, Figure 2).

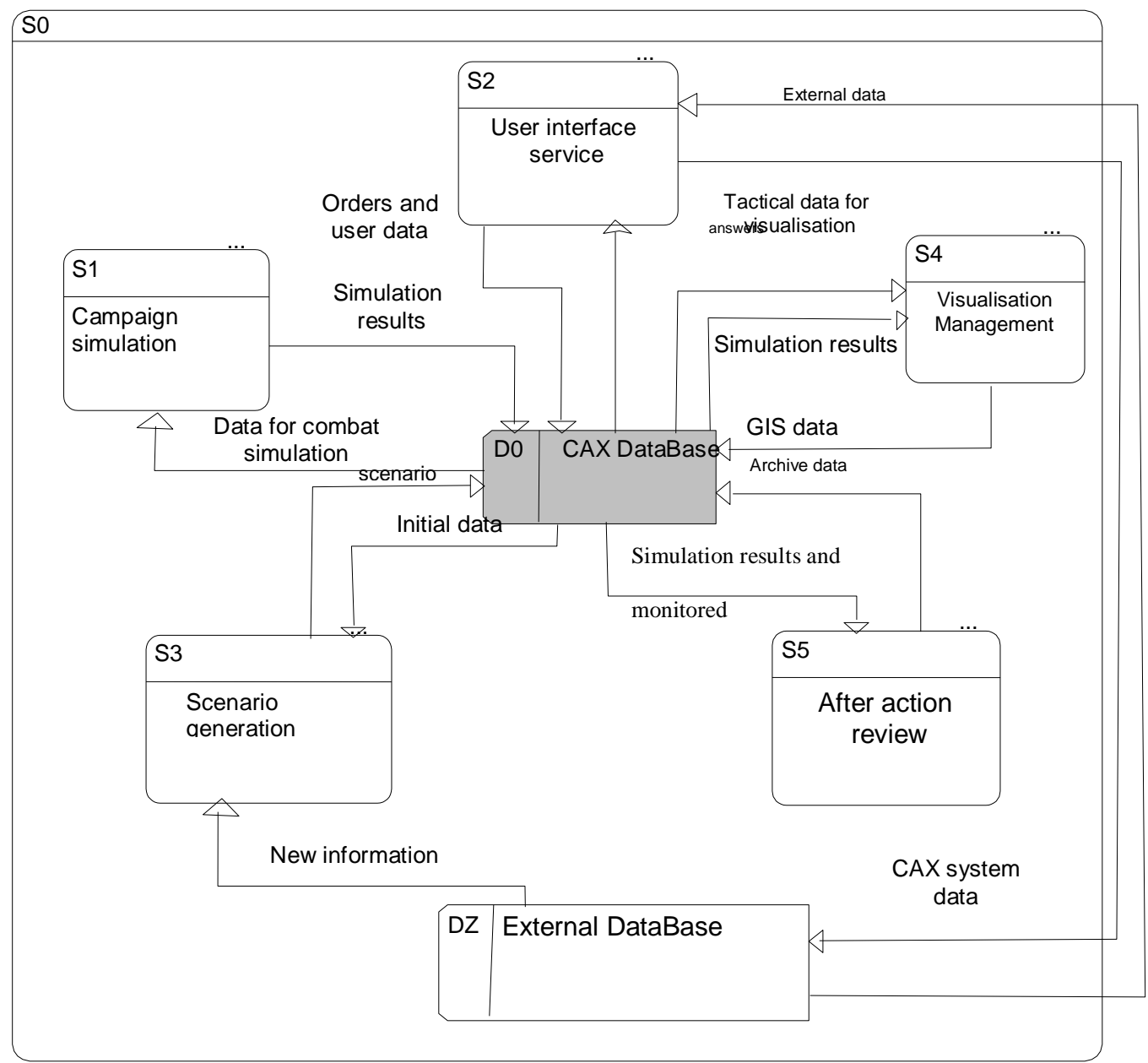

Figure 1. Data Flow Diagram of main process - "Computer Assisted Exercises"

The next step there is particular analysis of the components, separated on the 1st level. For example it is presented one of the main processes in the CAX system - simulation of campaign. 


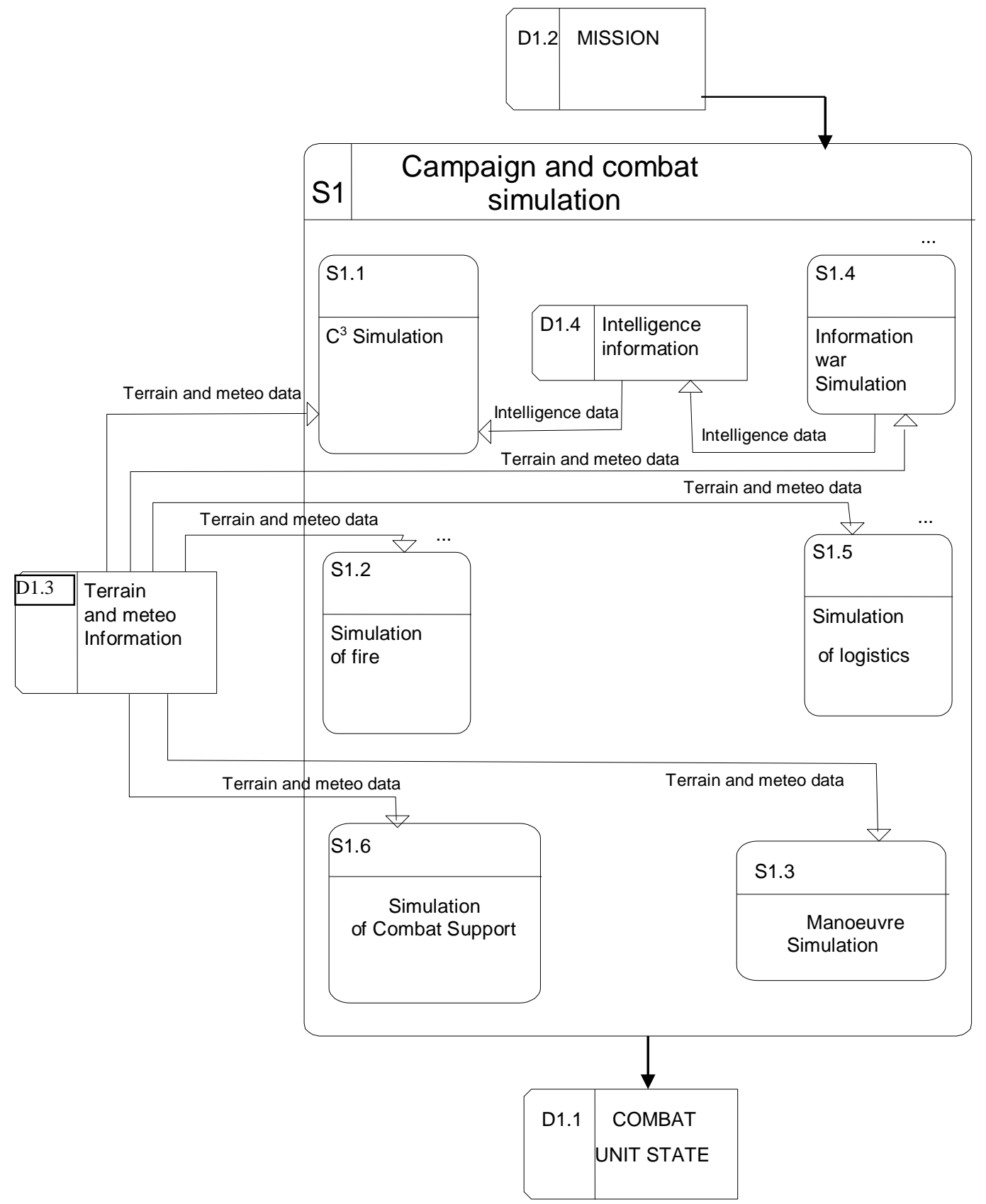

Figure 2. Data Flow diagram of campaign simulation process $\left(2^{\text {nd }}\right.$ level $)$

The two-level analysis is only an example of the designing process. Each of the components is described by formal model. In the case the conflict models should take into account:

- $\quad$ different forms of combat (defence, attack,...), the mobility of combat units (different combat rate), terrain conditions, overtaking of possible sides during combat actions, direct-fire and it results, ,inertia" of combat units, collaboration and synchronisation of neighbours troops, supply limits, the results of reconnaissance, the decision delays, $\mathrm{C} 2$ possibility.

Moreover, these models should: 
- reflect an uncertainty conditions, show the interaction of decision-maker, enable different survivability of own and enemy forces on depending on enemy action (force and direction), present deviation of combat unit trajectory as a result of counteraction of enemy, enable an observation of temporary results, present changes of combat characteristics, have stability in a sense of invariant rules describing the whole process, enable an evaluation of their sensitivity, enable an implementation on the computer, have possible the least complexity, enable the testing in a computer environment, enable the flexible changes of components if necessary.

The local combat models should answer for the question: what state of combat units will be after combat? Logistics models should supply an information: about movement of combat units on the, battlefield, connected with presentation of different strategies of resource supplying to combat units, about logistics characteristics for combat models.So the next model in the evolutionary process of professional simulation system designing there is (Najgebauer at al, 2002):

$$
S P W(t)=\left\langle S_{A}(t), S_{B}(t), R(t), S_{O}(t)\right\rangle
$$

where: $S_{A}(t), S_{B}(t)$ status vectors of the conflict sides; $R(t)=\left(R_{1}(t), R_{2}(t), \ldots, R_{L n}(t)\right)$ - vector of states of other conflict participants (e.g. state of civilian population, state of guerrillas, etc.);

$S_{O}(t)=\left(Z_{1}(t), Z_{2}(t)\right)$ - the state of the conflict environment describing: field conditions, meteorological conditions, engineering conditions, contamination, electromagnetic conditions, etc. It should be stressed that the states presented above will be random variables (for a fixed time $t$; in general, they will be stochastic processes). Randomness of the state for side A (own forces) may result from e.g. disturbances of the communication system, which causes that the information provided to the commander is incomplete. The randomness of the state for side B (enemy army) results from the fact that our information about this state comes from the recognition, which gives incomplete and uncertain information. The randomness of a state concerning the environment (weather, terrain) results from both uncertainty of the results transmitted from the reconnaissance (e.g. about the terrain) as well as from forecasts e.g. meteorological, which are of a random nature.

\section{THE IMPLEMENTATIONS}

One of sophisticated examples of interactive simulation environments can be our prototype MSCombat and real simulation system Złocien and SWDT, which are object oriented and base on the stochastic model $S(t)$ (2) the first one and $S P W(t)(5)$ battlefield model the second and third one. Many of their features can indicate the directions of development such environments. Primarily the environment was built to test possible solutions in simulation of land operations. The main point of view there was a technology. However many experiments for not so complicated situations were conducted and conclusions are very interesting. The main direction in the technological process there is High-Level Architecture rules utilisation, because one of most important requirements for Polish environments there is possibility of co-operation with NATO-countries simulation systems. This time the HLA is becoming the standard of communication and synchronisation of simulation environments. HLA consists of a number of interrelated components. The three that define HLA are: (1) the HLA rules, which define interoperability and what capabilities a simulation must have to achieve it within HLA; (2) the Object Model Template, which is a semi-formal methodology for specifying simulation and federation object classes, attributes, and interactions; and (3) the Interface Specification, a precise specification of the functional actions that a simulation may invoke, or be asked to perform, during an HLA exercise. The HLA Run-Time Infrastructure (RTI) is a software embodiment of the Interface Specification that implements the actions defined therein to be invocable by a simulation, provided as a set of services.

The deterministic and discrete time driven simulator SWDT models two-face land conflict of military units on the company/battalion level. The simulator is implemented in JAVA language as an integrated part of some system for CAXes. SWD-T is being used according to the following steps: the variant verification (via simulation) and the variant recommendation. Moreover, it can be also used for: (1) optimization of military units' command chains, (2) evaluation of the military operational rules and improving the command and control 
procedures, (3) research of military equipment's parameters which modify results of military actions, (4) verification quality of battlefield processes models (shooting, target searching, movement, etc.).

SWDT is a discrete time - driven simulator and models a two-face land conflict of military units on the company/battalion level. The inner models concern the couple processes of firing interaction and movement executed by a single military unit. These two complementary models use a terrain model described by a network of square areas which aggregates movement characteristics with $200 \mathrm{~m} \times 200 \mathrm{~m}$ granularity. The course of each process depends on many factors among them: terrain and weather conditions, states and parameters of weapons the units are equipped, type of executed units activities (attack, defence), distance between opponent units.

\section{THE EXERCISES AND AFTER ACTION REVIEW}

The professional system (Najgebauer at al, 2002, Najgebauer, 2004) consists of a number of software applications, which should be mentioned:

- Combat Simulator - the main part of the software responsible for simulating the situation on the battlefield. It implements all models of units, combat models and other types of operations, task interpreters, report generators, terrain model together with meteorological, engineering, radio electronic and contamination situation.

- Procedures for playing exercises - a package of procedures for playing exercises is an extension of the simulator that allows you to play the course of previously performed exercises.

- Calibration parameters editor - software used to modify the values of calibration parameters of models of actions and behaviours of active simulation objects (military units, elements of the battlefield). You can modify the default values of parameters (associated with each new scenario).

- Operational database - is embedded in Oracle database server (OLTP class). The database model has been defined using ORM technique for the object-oriented model of the information structure of the Złocien system. The database contains definitions of all ready-made scenarios together with all related elements. The operational base also includes elements related to the exercise being played according to the scenario. They include: descriptions of tasks set during the game, reports and periodically or incidentally recorded states of simulated elements.

- Map database - is embedded in Oracle database server (OLTP class). It contains tables describing such elements as point objects (e.g. bridges), linear objects (e.g. road sections, river sections), surface objects (forested areas, reservoirs), which were loaded from data available in VPF format, DTED height grid, as well as data describing squares converted on this basis (200x200 size, about 12.5 million squares in total) on which the combat simulator is based.

The analysis scheme is as follows: (1) the construction of different alternatives of combat, (2) the experimenting with monitoring of chosen characteristics (many replications); (3) the statistical analysis due to pattern of action and reaction recognition for different parameters of battlefield, (4) the comparison of battle results for different local combat models.

A scenario for the specific analysis can be presented as follows:

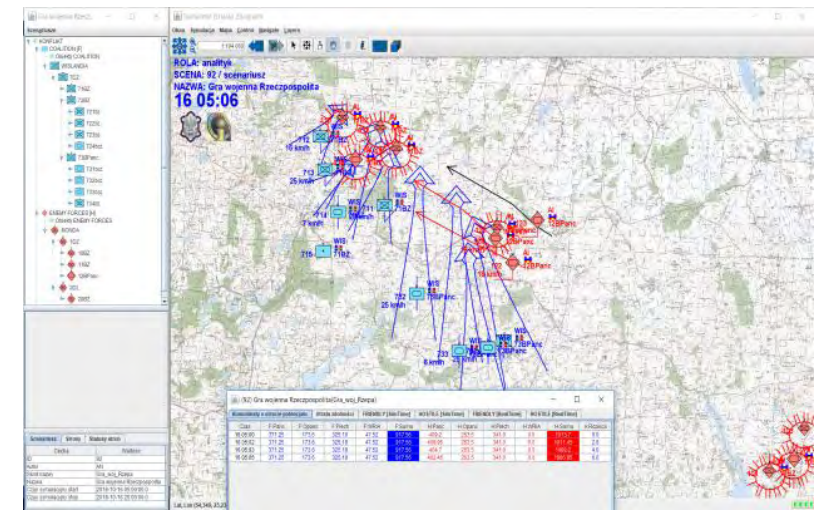

Figure 3. SWDT scenario and simulation of combat (own sources) 
Table 1. Selected combat simulation results for the scenario (Figure 3)

\begin{tabular}{|c|c|c|c|c|c|}
\hline Time & Side & Unit & Armt/mun & Code & Status \\
\hline 0 & 0 & $711 \mathrm{bz}$ & SPW & BWP-1 & 31 \\
\hline 0 & 0 & $711 \mathrm{bz}$ & SPW & KBKAK & 310 \\
\hline 0 & 0 & $711 \mathrm{bz}$ & SPW & RPG-7 & 60 \\
\hline 0 & 0 & $711 \mathrm{bz}$ & SPW & HS-2S1 & 8 \\
\hline$\ldots$ & $\ldots$ & $\ldots$ & $\ldots$ & $\ldots$ & $\ldots$ \\
\hline 0 & 0 & $711 \mathrm{bz}$ & MPS & ON & 30960 \\
\hline 0 & 0 & $712 \mathrm{bz}$ & SPW & BWP-1 & 31 \\
\hline 0 & 0 & $712 \mathrm{bz}$ & SPW & KBKAK & 500 \\
\hline 0 & 0 & $712 \mathrm{bz}$ & SPW & RPG-7 & 60 \\
\hline 0 & 0 & $712 \mathrm{bz}$ & SPW & HS-2S1 & 8 \\
\hline 0 & 0 & $712 \mathrm{bz}$ & AMO & $\begin{array}{l}\text { NB-PG-15W- } \\
73 \mathrm{~mm}\end{array}$ & 1224 \\
\hline 0 & 0 & $712 \mathrm{bz}$ & AMO & $\begin{array}{l}\text { NB-OG-15W- } \\
73 \mathrm{~mm}\end{array}$ & 816 \\
\hline 0 & 0 & $712 \mathrm{bz}$ & AMO & NB-7.62x39mm & 60000 \\
\hline$\ldots$ & $\ldots$. & $\ldots \ldots$ & $\ldots \ldots$ & $\ldots \ldots$ & $\ldots \ldots$ \\
\hline$\ldots$ & $\ldots$. & $\ldots \ldots$ & $\ldots \ldots$ & $\ldots \ldots$ & $\ldots \ldots$ \\
\hline 2100 & 1 & $203 \mathrm{bz}$ & MPS & $\mathrm{ON}$ & 20367 \\
\hline 2100 & 1 & $204 \mathrm{bcz}$ & SPW & T-80U & 31 \\
\hline 2100 & 1 & $204 \mathrm{bcz}$ & AMO & $\begin{array}{l}\text { NB-3WBM6- } \\
125 \mathrm{~mm}\end{array}$ & 1640 \\
\hline 2100 & 1 & $204 \mathrm{bcz}$ & AMO & NB-7.62x $54 \mathrm{~mm}$ & 82000 \\
\hline 2100 & 1 & $204 \mathrm{bcz}$ & AMO & $\begin{array}{l}\text { NB-NSW- } \\
12.7 \times 108 \mathrm{~mm}\end{array}$ & 8200 \\
\hline 2100 & 1 & $204 \mathrm{bcz}$ & MPS & $\mathrm{ON}$ & 65337 \\
\hline 2160 & 0 & $712 \mathrm{bz}$ & AMO & $\begin{array}{l}\text { NB-BK-6M- } \\
122 \mathrm{~mm}\end{array}$ & 0 \\
\hline 2160 & 0 & $712 \mathrm{bz}$ & MPS & $\mathrm{ON}$ & 0 \\
\hline 2160 & 0 & $713 \mathrm{bz}$ & SPW & BWP-1 & 0 \\
\hline 2160 & 0 & $713 \mathrm{bz}$ & SPW & KBKAK & 211 \\
\hline 2160 & 0 & $713 \mathrm{bz}$ & SPW & RPG-7 & 41 \\
\hline 2160 & 0 & $713 \mathrm{bz}$ & SPW & HS-2S1 & 1 \\
\hline 2160 & 0 & $713 \mathrm{bz}$ & AMO & $\begin{array}{l}\text { NB-PG-15W- } \\
73 \mathrm{~mm}\end{array}$ & 0 \\
\hline 2160 & 0 & $713 \mathrm{bz}$ & AMO & NB-7.62x $54 \mathrm{~mm}$ & 0 \\
\hline 2160 & 0 & $713 \mathrm{bz}$ & AMO & PK-9M14-125mm & 0 \\
\hline
\end{tabular}

A lot of data are generated during the simulation process (tab.1) and then the set of data is the main source of knowledge extracted in the process of after action review (described below) towards the learning and generalization some decision procedures.

After Action Reviews are conducted during training exercises as logical predetermined events (based on the exercise scenario) are completed and at the conclusion of the exercise to assist the commander in answering such questions as:

(1) What went right (or well) and wrong (or badly) during the exercise?

(2) What went better than expected during the exercise?

(3) How does the unit improve? 
The After Action Review Analyzer is a tool which enables checking selected game characteristic values off-line, after simulation. The characteristic are divided into a few categories as follows: state/resource levels of units (weapons, personnel, materials, potential), losses distribution of units regarding weapons, personnel, materials, potential (time distribution, structural distribution, time-structural distribution), schedule for units recognized by other units, task realization degree, real action speed, relation between real action speed and normative one. AAR Analyzer allows presentation of simulation results using tables and graphs. The tool can help in the process of data collecting for the learning of artificial intelligence based applications.

\section{THE TRANSITIONS OF DISTRIBUTED INTERACTIVE SIMULATIONS TOWARDS DECISIONS PATTERNS}

The transformation of interactive simulation environment into expert system there is multi-direction task. I wouldn't like to present complete transformation, however it could be very interested to obtain these decision patterns in a conflict situation. The pattern can be defined as an ordered pair of vectors:

$\xi=\langle\alpha, \beta>$, where: $\alpha$-vector of input magnitudes of the conflict situation, which fully identify the current state of the controlled system of $A(B)$-decision maker, $\beta$-vector of possible actions and its evaluations (risk, cost, effectiveness and so on ).

One of possible pattern acquisition there is an assortment of tendency model: $X(t)=f(t)+x(t)$ - model of chosen characteristics, side $A(B)$ losses in a moment $\mathrm{t}$, probability of wining in a moment $\mathrm{t}, f(t)$ - trend function (linear, lognormal, logistic, ...); $x(t)$ - random trend variation.

The scheme of model trend assortment is as follows: registration of characteristic realisation, estimation of trend model parameters, statistical verification of models, choice of the best model verified.

Another way there is rough set approach, where an information system: $I S=\langle O B J, A,\{V A L a\} a \in A\rangle O B J$ - universe of objects, $A$ - set of attributes, $V A L_{a}$ - domain of $a \in A$

Let's try to find any dependency between groups of attributes $\mathrm{P}$ and $\mathrm{Q}:(1) R(P)$ - an equivalence relation between objects from the set $P$ point of view, so we have $(O B J, R(P))$ - approximation space, $R *(P)$ - collection of equivalence classes of $R(P)$-objects with the same value of attributes belonging to $P$; (2) lower and upper approximation in the space $(O B J, R(P)): I N T(Y)=\cup\left\{X \in R^{*}(P): X \subseteq Y\right\} \quad U P P(Y)=\cup\left\{X \in R^{*}(P): X \cap Y \neq \varnothing\right\} I F$ $\operatorname{INT}(Y) \neq U P P(Y)$ then $Y$ is rough set,

(3) Let $R^{*}(Q)$ be a partition of $(O B J, R(P))$ and $R^{*}(Q)=\left\{Y_{1}, Y_{2}, Y_{3}, \ldots Y_{m}\right\}$ a measure of dependency is $\Sigma_{i}$ $\left(\operatorname{card}\left(I N T\left(Y_{i}\right)\right) / \operatorname{card}(O B J)\right.$. A rule with respect to a value $\mathrm{V}$ of the decision attribute $\left.\mathrm{d}: r=\left(a_{i, 1}=V_{i, 1}\right), \ldots,\left(a_{i, n}=V_{i, n}\right)\right\}$, where $A r=\left(a_{i, k}\right)_{k=1, . ., n} \subseteq A, r:\left(a_{i, 1}=V_{i, 1}\right) \wedge \ldots \wedge\left(a_{i, n}=V i, n\right) \rightarrow(d=V)-\operatorname{decision}$ rule. Quite interesting problem of knowledge generalization there is looking for fast response of local combat (Najgebauer et al. 2001). The local combat is defined as a clash of two formations, which consists in direct fire of two sides under optical visibility. The main purpose of local combat model construction is obtainment of answer for the question - how is resource decrease process running and how is fighting formations' location changing, when we know the state of the process before the battle?

The simulation process is time-consuming and the time of running depends on accuracy and the "granularity" of combat model. The proposal consists in construction of specific tool, which allows us to generate combat result very quickly. The generated combat result for the initial conditions determined (as a scenario) should provide an information about time of combat and the evaluation of formation's state.

The tool there is procedure of service of multidimensional table $G W=\left[g w_{i j \ldots k}\right]_{I \times J \times \ldots \times K}$ The element of the table $g w_{i j . . . k}$ there is vector of probability distributions (empirical) and / or regression function of output magnitudes. The input magnitudes are processes, which have many states. The particular element of a table can be identify by an index $(i, j, \ldots k)$ which describes number of an input magnitudes state. This generator can be used as: a tool for quick receiving of local combat result; an element of knowledge base for decision support system and simulation system; a method of comparison of different combat models; a method of evaluation of payoff in a theory game model (in armed conflict).

The most sophisticated idea was realized in the expert decision support system (Najgebauer, 2007), where the key term were decision situation and decision pattern situation: we can apply those elements for the decision situation vector definition, which contains knowledge about the terrain, military potential distribution in a 
combat formation and assigned tasks formulating a template for recognition process. We define a decision situations space and a set of patterns. We propose the measures of similarity and distance between the current decision-making situation and the model situation. On the basis of the selected closest (most similar) model situation to the current decision situation, a course of action of our own forces is build (Jędrzejowicz at al, 2011, Carlos Ramirez at al (eds), 2012). Some decision processes are based on approach in (Prekopa, 1995).

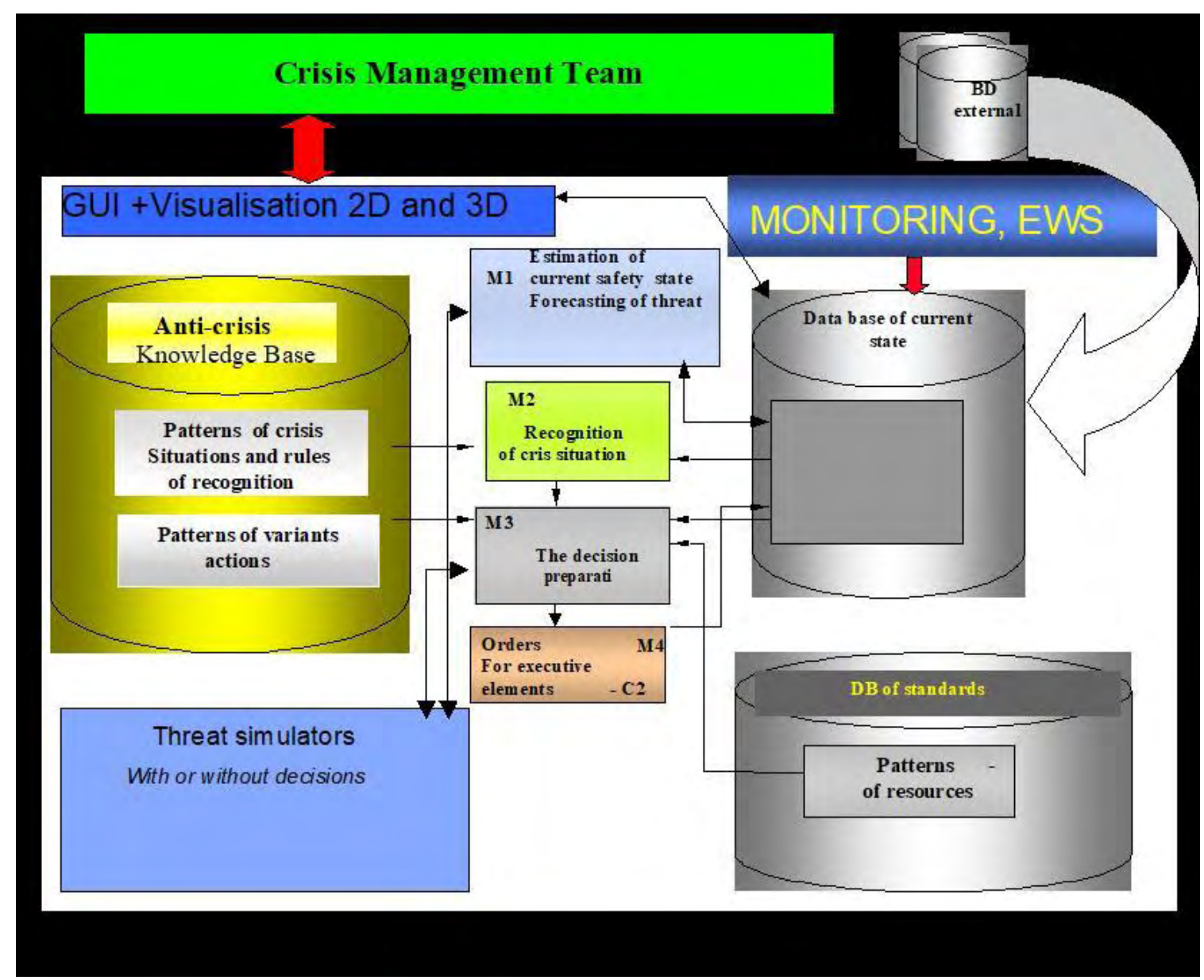

Figure 4. The idea of knowledge-based DSS (own sources- system "Guru” (Najgebauer at al, 2007)

\section{CONCLUSION}

Modelling and simulation with computer simulation environment presented have many applications within the defence and other than war processes. The principle domain of application is (see Clarke 1995, Hawkins 2000 as well): (1) as a training device for use at the individual, command team, and strategic levels, (2) as a tool for the conduct of campaign and mission rehearsal, and the analysis of operations, (3) as a device to assist the development of defence policy and doctrine, and the formulation of the equipment programme, (4) as a tool for testing the military equipment. The environment proposed is built as an opened system and can be developed and improved. The characteristics of battle process are being monitored during the simulation process and their statistical analysis allows combat actions predicting for different conflict situations (Figure 4) (see Carlos Ramirez (ed) 2012). The transition from interactive simulation environment into intelligent framework is being successfully realised and the collected data during simulations are big data set for learning the AI platform. Some interesting results are presented as the concept of CAST logic and stochastic PERT analysis to support military joint operation planning (see at Al-Begain $\mathrm{K}$ et al(eds), 2010). These methods were implemented in the computer package presented in the paper. By using the method and computer 
tool an exemplified military joint operation is considered. The system was built as a prototype knowledge-based decision support system and was tested in many computer assisted exercises organised in Polish Armed Forces (2007-2016). Author of the paper took part as an expert in the Strategic Defence Review and used described tools for the analysis of Armed Forces capabilities and also in the process of predicting of Armed Forces structure development.

\section{REFERENCES}

Al-Begain K., Fiems D., W. Knottenbelt (Eds.) 2010. ASMTA 2010, Chapter: Antkiewicz R, Gąsecki A, Najgebauer A, Pierzchała D, Tarapata Z, ,Stochastic PERT and CAST Logic Approach for Computer Support of Complex Operation Planning”, LNCS 6148, pp. 159--173. Springer, Heidelberg (2010).

Antkiewicz R., Kulas W., Najgebauer A., Pierzchała D., Rulka J., Tarapata Z., Wantoch-Rekowski R, 2007.: The Automation of Combat Decision Processes in the Simulation Based Operational Training Support System, Proceedings of the 2007 IEEE Symposium on Computational Intelligence in Security and Defense Applications (CISDA) 2007, ISBN 1-4244-0698-6, Honolulu (Hawaii, USA), April 1-5, 2007.

Carlos Ramirez (ed.) 2012. Advances in Knowledge Representation, INTECH, Rijeka, Croatia 2012. Chapter: Antkiewicz R, Chmielewski M, Drozdowski T, Najgebauer A, Rulka J., Tarapata Z, Wantoch-Rekowski R, Pierzchała D., Knowledge-Based Approach for Military Mission Planning and Simulation.

Clarke T.L., 1995- "Distributed Interactive Simulation Systems for Simulation and Training in the Aerospace Environment". SPIE Optical Engineering Press, USA, Orlando, 1995.

Dockery J., Woodcock A.E.R., (1993 - The Military Landscape, Mathematical Models of Combat, Published by Woodhead Publishing Ltd., Cambridge, England, 1993.

Hawkins G.P., 2000, - The UK MoD Requirement for Modelling and Simulation, Simulation for Military Planning, British Crown Copyright 2000. London.

Ilachinski J., 1996 - Land Warfare and Complexity, Part I: Mathematical Background and Technical Sourcebook, Centre for Naval Analyses, Alexandria, Virginia, USA, 1996.

Jędrzejowicz P., Nguyen N.T., Hoang K. (eds) 2011. Computational Collective Intelligence. Technologies and Applications. ICCCI 2011, Chapter: Antkiewicz R., Najgebauer A., Rulka J., Tarapata Z., Wantoch-Rekowski R. (2011) Knowledge-Based Pattern Recognition Method and Tool to Support Mission Planning and Simulation. Lecture Notes in Computer Science, vol 6922. Springer, Berlin, Heidelberg

Najgebauer A. (PM) et al. 2007. Technical reports on "Automated decision support tools - expert system" - "GURU". Military University of Technology, Warsaw 2005-2007.

Najgebauer A. 2004. Polish Initiatives in M\&S and Training. Simulation Based Operational Training Support System (SBOTSS) Zlocien, Proceedings of the ITEC'2004, London, UK, April 20-22 2004

Najgebauer A. et. al. 2002. Technical Project of Simulation System for Supporting Operational Training, Volume I-VI, Faculty of Cybernetics, MUT, Warsaw 2002. (Najgebauer A. - principal designer in the phase of research and development and PM in the phase of deployment process).

Najgebauer A., 1999a "Decision Support Systems for Conflict Situations. Models, Methods and the Interactive Simulation Environments" (in Polish). Ed. Bulletin WAT. Warsaw 1999, Poland. (294 p.). ISBN 83-908620-6-9

Najgebauer A., Nowicki T., Rulka J. 2001, "The Method of Construction and Learning of Local Combat Generator". Proceedings of Modelling \& Simulation Group Conference on Future Modelling and Simulation Challenges, NATO Modelling\&Simulation Group Conference in The Netherlands, Breda, 2001, November.

Najgebauer A., Pierzchała D., Rulka J., 1999b, "The Simulation Researches of Decision Processes in a Conflict Situation with Opposite Objectives". Proceedings of SCS International Conference ESM'99 June 1-4 1999, Warsaw Poland. (pp. 591-598).

Penrose R. 1989. The Emperor's New Mind. Concerning Computers, Minds, and the Laws of Physics. Oxford University Press 1989

Prekopa A., 1995 -Stochastic Programming Kluwer Academic Publisher, Dordrecht/Boston/London, ISBN 0-7923-3482-5. 